\title{
ENSEÑANZA DE LA HISTORIA, IDENTIDADES CULTURALES Y CONCIENCIA IBEROAMERICANA EN LOS LIBROS DE TEXTO ESPAÑOLES PARA EDUCACIÓN PRIMARIA
}

\author{
History teaching, cultural identities and Ibero-American \\ consciousness in Spanish primary education textbooks
}

\section{Delfín Ortega Sánchez ${ }^{ø}$ y Francisco Rodríguez Lestegás ${ }^{\S}$}

Fecha de recepción: 04/09/2016 • Fecha de aceptación: 05/02/2017

Resumen. Este artículo analiza el tratamiento curricular de la Historia de Iberoamérica y su contribución a la construcción de una conciencia iberoamericana en los libros de texto de Ciencias Sociales españoles para la Educación Primaria. Desde perspectivas inclusivas, interculturales e identitarias, aborda los mecanismos de consolidación y fortalecimiento del Espacio Cultural Iberoamericano en el ámbito educativo, examinando las narrativas históricas e iconográficas escolares, a partir del diseño, validación y aplicación de cinco instrumentos de recogida de datos, análisis y evaluación, integrados en cinco categorías de análisis: I. Identificación y clasificación iconográfica, II. Ordenación y función iconográfica, III. Narrativa histórica e identidad cultural, IV. Actividades e identidad cultural, v. Validación curricular.

Los resultados informan de la sólida adopción de perspectivas eurocéntricas y hegemónicas frente a la ausencia elocuente de una verdadera capacidad integradora de contenidos sociales, culturales e históricos orientados a la consolidación del Espacio Cultural Iberoamericano y a la construcción de la reconocida identidad cultural iberoamericana.

Palabras clave: Enseñanza de la Historia de Iberoamérica; Espacio Cultural Iberoamericano; Conciencia iberoamericana; Identidad cultural iberoamericana; Libros de Texto de Ciencias Sociales.

\footnotetext{
${ }^{\varnothing}$ Departamento de Didácticas Específicas. Facultad de educación. Universidad de Burgos. C/ Villadiego, s/n. 09001 Burgos. España. dosanchez@ubu.es

$\S$ Departamento de Didácticas Aplicadas. Facultad de Formación del Profesorado. Universidad de Santiago de Compostela. Avda. de Ramón Ferreiro, s/n. 27002 Lugo. España. f.lestegas@usc.es
}

Cómo citar este artículo: Ortega Sánchez, Delfín y Rodríguez Lestegás, Francisco. «Enseñanza de la historia, identidades culturales y conciencia iberoamericana en los libros de texto españoles para educación primaria», Historia y Memoria de la Educación, 6 (2017): 279-318. 
Abstract. This article analyzes the curricular treatment of Ibero-American history and the construction of an Ibero-American consciousness in Spanish primary education social studies textbooks. From inclusive and intercultural perspectives, the study approaches the mechanisms of consolidation and strengthening of the Cultural Ibero-American Space in the educational realm. It examines the historical and iconographic school narratives by means of the design, validation and application of five instruments for the data collection, analysis and evaluation, integrated into five categories of analysis: $i$. Identification and iconographic classification, ii. Ordering and iconographic function, iii. Historical narrative and cultural identity, iv. Activities and cultural identity, $v$. Validation. The results confirm the solid adoption of Eurocentric and hegemonic perspectives resulting from the absence of any real capacity for integrating social, cultural and historical contents or working towards to the consolidation of a Cultural Ibero-American Space or the construction of an Ibero-American cultural identity. The results report of the solid adoption of eurocentral and hegemonic perspectives opposite to the eloquent absence of a real of integration capacity of social, cultural and historical contents orientated to the consolidation of the Cultural Ibero-American Space and the construction of the recognized Ibero-American cultural identity.

Keywords: Teaching of Ibero-American History; Ibero-American Cultural Space; Ibero-American consciousness; Ibero-American cultural identity; Social studies textbooks.

\section{DIMENSIÓN EDUCATIVA DE LA CARTA CULTURAL IBEROAMERICANA: IDENTIDAD EN LA DIVERSIDAD}

Puede afirmarse, con seguridad, que la Comunidad Iberoamericana de Naciones constituye una comunidad cultural que, delimitada en la diversidad no yuxtapuesta, se presenta como un todo integrado, tal y como evidenció la creación de la Carta Cultural Iberoamericana (CCI). El documento, aprobado en la IX Conferencia Iberoamericana de Cultura y firmado en la XVI Cumbre Iberoamericana de Jefes de Estado y de Gobierno en 2006, supone el marco prescriptivo y vinculante para la definición de la identidad cultural iberoamericana - eje colectivo de vertebración de una comunidad diversa con lenguas y culturas compartidas-, capaz de garantizar la cooperación e integración cultural de los pueblos desde su diversidad, la creación de espacios propios de circulación cultural y la articulación de mecanismos para la mejora del conocimiento del sustrato y riqueza cultural de los países miembros. La carta se convierte, por tan- 
to, en una importante herramienta para la promoción y protección de la diversidad cultural de los países que la suscriben - marca distintiva de la cultura iberoamericana-, y para la coordinación en materia patrimonial e industria cultural.

El texto, lejos de concebirse como una declaración teórica de intenciones, supone un verdadero plan de acción para la puesta en marcha de políticas culturales y una propuesta definida para el fomento de la conciencia identitaria iberoamericana. El «Preámbulo» de la CCI recuerda los principios enunciados en la Declaración de la I Cumbre Iberoamericana -Guadalajara, México, 1991- y afianza en los países miembros su representación como «vasto conjunto de naciones que comparten raíces y el rico patrimonio de una cultura fundada en la suma de pueblos, sangres y credos diversos», ${ }^{1}$ cuya convergencia radica en un acervo cultural común y en su riqueza plural. Igualmente, considera y entiende el ejercicio de la cultura como una dimensión de la ciudadanía, elemento de cohesión e inclusión social generador de confianzas y autoestimas individuales, nacionales y comunitarias.

En esta línea, el documento recoge en sus «Fines» el reconocimiento de la existencia del Espacio Cultural Iberoamericano como ámbito propio y singular, la necesidad de su cooperación con otros espacios mundiales, y el fomento de la protección y la difusión del patrimonio cultural y natural, material e inmaterial, testigo de la evolución de las comunidades iberoamericanas. Desde esta realidad patrimonial, referencia básica de identidad, contempla el ámbito de aplicación específico «Patrimonio Cultural», en el que se prescribe, a través de las manifestaciones culturales y lingüísticas que les son propias, su protección, transmisión y promoción.

El fundamento histórico-cultural que asume la creación de la Comunidad Iberoamericana de Naciones determina el interés por desentrañar los aspectos definitorios de la identidad iberoamericana y distinguir sus elementos compositivos. ${ }^{2}$ De acuerdo con la Organización de Estados Iberoamericanos, «la identidad iberoamericana se conforma en base al

\footnotetext{
${ }^{1}$ Carta Cultural Iberoamericana, 2006. http://www.culturasiberoamericanas.org/carta_cultural.php (consultado el 13-3-2012).

${ }^{2}$ Cástor Díaz Barrado, «Algunas reflexiones sobre la identidad en el seno de la Comunidad Iberoamericana de Naciones», Investigación \& Desarrollo, 21 (2), (2013): 419-454.
} 
encuentro de múltiples expresiones culturales, que al manifestarse en un conjunto de elementos en común le otorgan un carácter singular». ${ }^{3}$ De este modo, la articulación de esta identidad plural se asienta en la diversidad cultural de los Estados que compone el mapa de la comunidad y se orienta hacia la definición de patrones identitarios, cristalizados en su patrimonio cultural tangible e intangible. ${ }^{4}$ La configuración de la identidad iberoamericana debe entenderse, entonces, como un proceso en continua formación y como un rico producto del diálogo cultural, ${ }^{5}$ verificado en el Espacio Cultural Iberoamericano, impulsado en su proyección mundial y ratificado por la Declaración de Panamá en la XXIII Cumbre. Este espacio, definido como proyecto unitario de cooperación cultural, a partir de valores simbólicos gestados en la experiencia histórica compartida y asentada en un ámbito geográfico supranacional, ${ }^{6}$ asumen el ámbito de la cultura como su principal factor de cohesión, tal y como prescribe la CCI, demuestra la proclamación de Embajadores Iberoamericanos de la Cultura ${ }^{7}$ y reitera la Resolución sobre la Renovación de la Conferencia Iberoamericana de 2013.

De especial importancia para esta investigación resulta el ámbito de aplicación «Cultura y Educación». Evidenciada la estrecha relación entre educación y cultura, la CCI prescribe, entre otras líneas de actuación, la necesidad de reforzar el conocimiento y la valoración de la diversidad cultural iberoamericana en los sistemas educativos, y el fomento curricular de una perspectiva regional del aprendizaje. En este marco espacial supranacional y, en cumplimiento de los fines, principios y ámbitos de la CCI, se manifiesta la voluntad internacional de reafirmar la existencia de una identidad cultural iberoamericana, mediante el fortalecimiento estructural de cooperación para la visibilidad unitaria de Iberoamérica en el contexto global.

\footnotetext{
${ }^{3}$ Organización de Estados Iberoamericanos. Iberoamérica: unidad cultural en la diversidad. http:// www.dgri.sep.gob.mx/formatos/4_oei_13.pdf (consultado el 3-3-2014).

${ }^{4}$ XXIII Cumbre Iberoamericana de Jefes de Estado y de Gobierno 2013. http://segib.org/es/node/8417 (consultado el 11-2-2014).

${ }^{5}$ XXIII Cumbre Iberoamericana de Jefes de Estado y de Gobierno 2013.

${ }^{6}$ Informe sobre la consolidación del Espacio Cultural Iberoamericano 2013. http://segib.org/es/node/9150 (consultado el 7-2-2014).

${ }^{7}$ Fernando García Casas, «Un lugar para la Comunidad Iberoamericana», Política exterior, 27 (151), (2013): 161-162.
} 
Entre las propuestas específicas contempladas en el Informe sobre la consolidación del Espacio Cultural Iberoamericano, resultan especialmente importantes para el ámbito de la Didáctica de las Ciencias Sociales las referidas a la dimensión social y ciudadana, la dimensión histórico-patrimonial y, de forma prioritaria, la dimensión educativa y del conocimiento.

Dimensión social y ciudadana: El Espacio Cultural Iberoamericano ha de estimular una conciencia compartida en la ciudadanía cultural iberoamericana, garantizando la participación en su diversidad simbólica y el reconocimiento recíproco de identidades complejas y plurales.

Dimensión histórico-patrimonial: El espacio cultural habrá de posibilitar la puesta en valor, conocimiento y difusión de las manifestaciones culturales materiales e inmateriales, referenciales para la identidad cultural iberoamericana. Para tal fin, se propone, entre otras medidas, la difusión del conocimiento de bienes culturales a través de los distintos diseños curriculares.

Dimensión educativa y del conocimiento: desde esta dimensión, el espacio operará en la cultura, la educación y el conocimiento como una unidad conceptual, aproximando el ámbito educativo, intelectual, social, económico y cultural.

La cultura y el conocimiento, como soportes de la inteligencia colectiva, ofrecen las experiencias necesarias para su instrumentalización en recursos de convivencia. En este sentido, la educación habrá de asumir un rol, capaz de garantizar la disposición de estos elementos por parte de la sociedad. Para ello, y subrayando las líneas que a este respecto define la CCI, deberá:

a) Incorporar en los currículos contenidos de la cultura y de la historia iberoamericana, reafirmando los componentes propios e identitarios.

b) Reforzar el conocimiento y la valoración de la diversidad cultural iberoamericana en los sistemas educativos.

c) Favorecer la incorporación en los planes educativos y, en sus respectivos territorios, de las lenguas, valores y conocimientos de las comunidades tradicionales e indígenas. 
d) Favorecer la incorporación, en planes y programas educativos, de líneas temáticas dirigidas al fomento de la creatividad y la formación de públicos culturalmente críticos.

Superados los mecanismos civilizatorios de homogeneización cultural, la visibilidad de un espacio cultural en la región iberoamericana pasa por la necesidad de evidenciar su heterogeneidad y complejidad cultural, habilitando circuitos de intercambio, diálogo y comunicación. De esta manera, «además de identificar lo que nos es común, es fundamental su conocimiento e intercambio ${ }^{8}$ en el espacio de comunidades históricas cohesionadas por sus lenguas, motores de representación e identidad.

Sin embargo, es constatable el desconocimiento mutuo manifiesto por las comunidades de la región iberoamericana y la supervivencia de tópicos y estereotipos que entorpecen, seriamente, el diálogo intercultural para el auto-conocimiento. La concepción y fortalecimiento de identidades complejas compartidas sólo será posible en el ejercicio de una ciudadanía crítica con aquello que le es propio y en contextos políticos, sociales y culturales óptimos para su participación activa, evitando tendencias hacia fundamentalismos culturales que nieguen la comprensión mutua y la necesaria comunicación horizontal de la cultura.

La cooperación cultural, articulada en ejercicios simétricos de decisión por los Estados miembros, ha de basarse en intercambios culturales y simbólicos equitativos, alejando hegemonías y dependencias, e incentivando y desarrollando lazos de solidaridad sobre los valores culturales propios y compartidos, tal y como han demostrado las celebraciones de los Bicentenarios, promotoras de la diversidad cultural y de un sólido bloque social y cultural.

Esta unidad en la diversidad, característica de la dimensión iberoamericana, requiere de programas de formación, también en los centros académicos formales, con materias específicas sobre la realidad cultural iberoamericana y diseños metodológicos inclusivos. Ya desde la creación de la Cátedra de Historia de Iberoamérica en la Cumbre de La Habana de 1999, se constató el escaso desarrollo que la Historia de Iberoaméri-

\footnotetext{
${ }^{8}$ Álvaro Marchesi (coord.), Avanzar en la construcción de un espacio cultural compartido. Desarrollo de la Carta Cultural Iberoamericana (Madrid: Organización de Estados Iberoamericanos para la Educación, la Ciencia y la Cultura, 2012), 46.
} 
ca recibía en los sistemas educativos de la comunidad y la necesidad de generar en las sociedades iberoamericanas «consensos favorables a la integración regional, mediante un más profundo y acabado conocimiento de los puntos comunes de los procesos históricos constitutivos de los países». ${ }^{9}$ Se apostaba por una educación integral de calidad, articulada en la formulación de políticas «que contemplen la profundización de la identidad cultural iberoamericana y que la enseñanza de la historia, en este caso común a los países, es un elemento clave para fortalecer el espacio cultural iberoamericano y forjar los vínculos que reconocen hoy los países iberoamericanos como miembros de una comunidad». ${ }^{10}$ En esta línea, concretaba como objetivo general:

Contribuir al desarrollo y consolidación de la Comunidad Iberoamericana de Naciones a través del fortalecimiento y afirmación de su identidad regional compartida, avanzando en un mayor y más profundo conocimiento crítico de los procesos históricos que subyacen a su matriz cultural común. ${ }^{11}$

La cultura iberoamericana se presenta, por tanto, como «una gran manifestación, al igual que la europea, de la modernidad cultural» ${ }^{12}$ propia, pero que, a diferencia de ésta, se caracteriza por una variada y profunda hibridación cultural de raíz originaria, afrodescendiente y europea; una realidad singular cuya respuesta y responsabilidad educativa reside en los diseños curriculares de los países de la región.

\section{IBEROAMÉRICA EN LA EDUCACIÓN BÁSICA: UN PROYECTO DE HISTORIA E IDENTIDAD REGIONAL COMÚN}

Es cierto que en los sistemas educativos de numerosos países del ámbito iberoamericano, las narrativas históricas continúan reflejando posiciones nacionales de expresión mayoritaria. Éstas alejan otras realidades, tendiendo a la proposición de personajes y hechos memorables, más próximos a construcciones míticas o versiones del pasado que al

\footnotetext{
${ }^{9}$ Organización de Estados Iberoamericanos. Cátedra de Historia de Iberoamérica. Documento programático 2001. http://www.campus-oei.org/cathistoria/ (consultado el 1-3-2012).

${ }^{10}$ Organización de Estados Iberoamericanos, Cátedra de Historia de Iberoamérica.

${ }^{11}$ Organización de Estados Iberoamericanos, Cátedra de Historia de Iberoamérica.

${ }^{12}$ Informe sobre la consolidación.
} 
conocimiento historiográfico. Efectivamente, en orden a las dimensiones explicativas de las narrativas nacionales y, específicamente, desde su concepción ontológica y esencialista de la nación y de sus habitantes, estas narrativas, en su intento por simplificar el desarrollo de los eventos históricos, reducen al sujeto histórico participante en grupos particularistas; «si bien el sujeto de las narrativas nacionales podría ser colectivo, sus rasgos coinciden con los de un solo grupo particular». ${ }^{13}$

No cabe duda de que sigue siendo evidente el cumplimiento de una de las principales finalidades educativas de las narrativas históricas nacionales: «la creación y el mantenimiento de un sentido de identidad nacional entre sus ciudadanos; configurando a su vez las posibles interpretaciones del contenido histórico». ${ }^{14}$ Los libros de texto se convierten aquí en uno de los instrumentos de mayor producción, difusión y garantía de recepción de estas narrativas históricas, amplificando «la voz oficial, y a menudo única, del Estado-Nación» ${ }^{15}$ y proponiéndose a maestros/as y alumnos/as, principalmente, de Educación Primaria, como una referencia acabada y verdadera del conocimiento como construcción social. En efecto, «el texto escolar o manual de historia todavía se presenta como fundamental a la hora de enseñar historia patria». ${ }^{16}$

A diferencia de los textos especializados de investigación histórica, la tramitación masiva del pasado en los currículos y libros de texto escolares pasa, como tradicionalmente ha venido liderando la enseñanza de la historia nacional, ${ }^{17}$ por lo socialmente conveniente, traducido en la definición de bases para la configuración de una identidad que opera como mediadora entre el/los Estado/s y la ciudadanía hacia un proyecto conjunto de futuro. Los LTG - Libros de Texto Gratuitos- de la escuela primaria mexicana, editados por el propio Estado, es una clara evidencia

\footnotetext{
${ }^{13}$ Mario Carretero y María Sarti, «Notas sobre la enseñanza de la historia en Iberoamérica. La centralidad de las narrativas nacionales», Íber: Didáctica de las Ciencias Sociales, Geografía e Historia, 75 (2013): 40.

${ }^{14}$ Carretero y Sarti, «Notas sobre la enseñanza de la historia en Iberoamérica», 36.

${ }^{15}$ Carretero y Sarti, «Notas sobre la enseñanza de la historia en Iberoamérica», 36.

${ }^{16}$ Carolina Campos Chávez, Identidad nacional y enseñanza de la historia en la escuela. Una aproximación al caso mexicano y chileno (Tesis de Máster en Enseñanza de la Historia, Universidad Michoacana de San Nicolás de Hidalgo, 2012), 50.

${ }^{17}$ Mario Carretero, Documentos de identidad. La construcción de la memoria histórica en un mundo global (Buenos Aires: Paidós, 2007).
} 
de ello. La concreción de los planes y programas de estudio en su organización curricular los convierten en una "parte integral del quehacer docente en la educación básica nacional y un referente de lo que un niño de primaria debe saber [...], garantía para el logro de los propósitos educati$\operatorname{vos}[\ldots][y]$ paradigma de conocimiento que todo niño debería lograr». ${ }^{18}$

Frente a esta perspectiva, esencialmente, nacionalista, más evidente en los países latinoamericanos, en el contexto español la enseñanza de la Historia de Iberoamérica se posiciona en una dimensión eurocéntrica, destacando, inicialmente, los avances científico-técnicos producidos para hacer posible la llegada europea a tierras americanas y las consecuencias político-económicas del encuentro para la monarquía hispánica y para Europa. ${ }^{19}$

Sobre el esencialismo nacionalista y dimensional europeísta, se impone la necesidad de trazar planteamientos historiográficos transnacionales, capaces de favorecer el diálogo intercultural, y la comprensión y posterior tratamiento didáctico de la diversidad cultural, presente en la realidad social, cultural y educativa de los países del ámbito iberoamericano. ${ }^{20}$ Sin embargo, un somero análisis del currículo de Educación Primaria y del primer ciclo de Secundaria Obligatoria, arrojan datos

${ }^{18}$ Verónica Arista, Felipe Bonilla y Laura H. Lima, «Los manuales escolares y su uso en el aula», Íber: Didáctica de las Ciencias Sociales, Geografía e Historia, 70 (2012): 23-28.

${ }^{19}$ Ilaria Bellatti y Virginia Gámez, «La historia de Iberoamérica en los currículos escolares: Un enfoque intercultural», Íber: Didáctica de las Ciencias Sociales, Geografía e Historia, 75 (2013): 43-50.

${ }^{20}$ En los últimos años, la atención a la diversidad constituye uno de los principios rectores del sistema educativo español. La concreción de esta diversidad cultural ha venido explicándose en los conceptos de interculturalidad, multiculturalidad o pluriculturalidad, todos ellos alusivos a la "coexistencia, en un mismo medio social, de personas procedentes de distintas culturas, del desafío que tal coexistencia plantea y de la necesidad de propiciar entre la población actitudes de no discriminación por razón de origen, etnia, idioma, cultura o religión». M. ${ }^{a}$ del Carmen González Muñoz, Una respuesta didáctica a la multiculturalidad: el tratamiento en las aulas de Educación Secundaria de la historia común de Iberoamérica (Madrid: Viceconsejería de Educación de la Comunidad de Madrid / Subdirección General de Inspección Educativa, 2005), 5. En contextos educativos diversos, como los actuales, pueden reconocerse tres corrientes metodológicas enfrentadas: una primera, mantenida, al menos, hasta los años sesenta, que conduce sus principios hacia la aculturación del discente de origen extranjero, postura no superada en algunos espacios democráticos de la actualidad como en los Países Bajos; una segunda, dirigida hacia la negación de la materia de Historia, por su responsabilidad en la transmisión de referentes culturales o nacionalistas. Fue el caso de Canadá en los años ochenta; y una tercera, más próxima a la idea de interculturalidad y más aceptada, que, aun manteniendo en los currículos los referentes identitarios nacionales, incluye otras realidades culturales. De esta manera, mediante el conocimiento de las dimensiones colectivas de carácter étnico y cultural del nosotros, se accede al conocimiento del otro desde esas mismas dimensiones. Pedro Miralles y Sebastián Molina, «La importancia de los referentes nacionales en el aprendizaje de las Ciencias 
abrumadores en los que el componente político y económico desplaza al social y cultural de las sociedades y culturas intervinientes en tres siglos de historia común. Como bien apuntan Bellati y Gámez, ${ }^{21}$ la mención a las civilizaciones prehispánicas se inscribe en una perspectiva histórica que las sitúa en tiempos históricos atemporales y las explica en función de «qué se encontraron los europeos en su llegada al continente americano", invisibilizando a las sociedades y culturas americanas en este proceso histórico.

De acuerdo con los primeros resultados del Proyecto de Investigación La enseñanza de la historia y la construcción de las identidades culturales: los procesos de cambios conceptuales en el ámbito de la enseñanza y el aprendizaje de centros escolares iberoamericanos y españoles -I+D EDU2009-09425-, al finalizar la Educación Secundaria Obligatoria en España, el alumnado, de procedencia latinoamericana y española, evidencia serias carencias de conocimientos en aspectos geográficos e históricos básicos sobre Iberoamérica. Según estos datos, se hace necesario «un replanteamiento curricular y, sobre todo, didáctico de la historia iberoamericana que propicie aprendizajes sólidos y que genere sentimientos de empatía y de respeto hacia la alteridad", ${ }^{22}$ fomente la interculturalidad y proyecte una historia iberoamericana, más allá de los límites nacionales.

Tal y como también han demostrado otros estudios en Alemania y Estados Unidos, Miralles y Molina ${ }^{23}$ constatan un buen conocimiento geográfico e histórico cuando éste aparece directamente vinculado al país de procedencia del alumno/a. Esta circunstancia reafirma la dificultad de considerar «que estos alumnos tengan un concepto de Iberoamérica como elemento identitario unificador», afirmación, aseveran en princi-

\footnotetext{
Sociales: una investigación con alumnado iberoamericano», Íber: Didáctica de las Ciencias Sociales, Geografía e Historia, 75 (2013): 57-66.

${ }^{21}$ Bellatti y Gámez, «La historia de Iberoamérica en los currículos escolares», 43-50.

${ }^{22}$ Joan Miquel Albert y Concha Fuentes, «Enseñanza de la historia y construcción de identidades culturales en centros escolares iberoamericanos y españoles», Íber: Didáctica de las Ciencias Sociales, Geografía e Historia, 75 (2013): 55; Concha Fuentes y Virginia Gámez, "¿Qué saben los alumnos de secundaria de la geografía iberoamericana?», en Innovación en la enseñanza de la geografía ante los desafíos sociales y territoriales, coords. Rafael de Miguel, M. ${ }^{a}$ Luisa de Lázaro y Torres y M. ${ }^{a}$ Jesús Marrón (Zaragoza: Institución Fernando el Católico, 2013), 239.

${ }^{23}$ Miralles y Molina, «La importancia de los referentes nacionales en el aprendizaje de las Ciencias Sociales», 57-66.
} 
pio, nada extraña «si se considera que en cada país iberoamericano se enseña la historia y la geografía de ese país, y no la de Iberoamérica». ${ }^{24}$ En definitiva, puede decirse que «el marco identitario en el que se mueve el alumnado iberoamericano que vive y estudia en España es más nacional que iberoamericano». ${ }^{25}$

A tenor de los resultados obtenidos, esta misma lectura puede realizarse en la investigación de las profesoras Fuentes y Gámez, ${ }^{26}$ a partir de las respuestas a un interesante cuestionario sobre conocimientos geográficos iberoamericanos, devueltas por una amplia muestra de alumnado latinoamericano y español de Educación Secundaria Obligatoria. La pregunta cinco "¿qué países integran Iberoamérica?» proponía cuatro respuestas posibles, directamente ligadas a la definición de identidad cultural iberoamericana: los países que hablan español; los países que formaron parte de la corona española y portuguesa; los países de Sudamérica; los países latinos que comparten un tipo de música y religión. ${ }^{27}$ Los resultados informan que un 39.3\% relacionaba correctamente Iberoamérica con los territorios que formaron parte de la monarquía hispánica y portuguesa; un $47.8 \%$ la fallaba y un $12.4 \%$ no la contestó o no optó por una posible respuesta. En el mayoritario porcentaje de respuestas incorrectas, destacó la definición de Iberoamérica como un conjunto de países pertenecientes a Sudamérica $-26.8 \%$ - En este caso, considerando los resultados por procedencia del alumnado, no se advirtieron diferencias destacables, presentando un panorama general de conocimientos medio-bajo.

Detectada y, ampliamente, demostrada esta carencia, son conocidos los programas nacionales e internacionales, ${ }^{28}$ dedicados a plantear una

\footnotetext{
${ }^{24}$ Miralles y Molina, «La importancia de los referentes nacionales en el aprendizaje de las Ciencias Sociales», 65.

${ }^{25}$ Miralles y Molina, «La importancia de los referentes nacionales en el aprendizaje de las Ciencias Sociales», 65 .

${ }^{26}$ Fuentes y Gámez, «¿Qué saben los alumnos de secundaria de la geografía iberoamericana?», 227-239.

${ }^{27}$ Fuentes y Gámez, «¿Qué saben los alumnos de secundaria de la geografía iberoamericana?», 235.

${ }^{28}$ En 1993 la Organización de Estados Iberoamericanos para la Educación, la Ciencia y la Cultura marcó como objetivo la armonización de la enseñanza de la Historia de Iberoamérica, a través del proyecto «Armonización e innovación de la enseñanza de la Historia en Iberoamérica». Dos fueron los objetivos generales: analizar la situación y formular sugerencias y propuestas para la mejora de la enseñanza de la Historia en el nivel medio en Iberoamérica. Los resultados obtenidos destacaron, entre otras conclusiones, la descoordinación entre los currículos de enseñanza básica del ámbito iberoamericano, por la que sólo diez países de los veintidós incluían la Historia de América como
} 
Historia de Iberoamérica que priorice los procesos histórico-culturales comunes a las sociedades protagonistas; máxime, cuando los importantes flujos migratorios actuales en el interior de la región iberoamericana ofrecen una extraordinaria oportunidad para poner en marcha tratamientos didácticos inclusivos de una historia y culturas de la que las distintas nacionalidades, desde su diversidad, forman parte. La posible dificultad de esta inclusión, en cualquier caso, atenuada por la utilización de una lengua común,

se vería muy suavizada con un tratamiento escolar y curricular adecuado que permitiese el conocimiento y el aprecio del patrimonio histórico y cultural común, atendiendo a su diversidad pluricultural y plurilingüe así como el respeto y la valoración de las creencias, actitudes y valores de ese acervo. ${ }^{29}$

En esta línea, una nueva reflexión curricular de la enseñanza de la idea de Iberoamérica, desde la Educación Primaria, orientada al fomento de hábitos de convivencia y solidaridad, la comprensión entre pueblos y la interculturalidad, posibilitaría al alumnado iberoamericano de uno y otro lado del Atlántico, el reconocimiento en su propia identidad y en un espacio cultural iberoamericano supranacional.

Según los resultados de los análisis de los currículos de la Educación Básica iberoamericana, ya anunciados por la Organización de Estados

materia escolar. Igualmente, se observó la sustitución del concepto de Iberoamérica, a partir del tratamiento de la Independencia, por la yuxtaposición de datos localistas relativos a las respectivas historias nacionales, obviando los factores comunes a ese proceso histórico. Desde la formulación de estos primeros objetivos para la armonización curricular entre los países iberoamericanos, en 1998 se propuso un currículum-tipo de Historia de Iberoamérica para el nivel medio de enseñanza obligatoria, apoyado por la vII Cumbre Iberoamericana de Jefes de Estado y de Gobierno - Venezuela, 1997- y presentado para su aprobación en la reunión de consulta celebrada en México en 1998; fue el primer intento didáctico de una historia común entre los países ibéricos y los latinoamericanos. Al final de la etapa para la que destina el currículo, habrán de haberse alcanzado los objetivos generales previstos: «el conocimiento de los hechos y procesos más significativos del pasado de Iberoamérica, una identificación emocional entre los hombres y los pueblos iberoamericanos que complemente otras identidades, como la etnia y la cultura a la que pertenecen y la nación de la que son ciudadanos, y ayude a desarrollar una educación intercultural». Instituto de Estudios de Iberoamérica y Portugal. Universidad de Valladolid, «La enseñanza de la historia de Iberoamérica: el primer proyecto de una historia común», Íber: Didáctica de las Ciencias Sociales, Geografía e Historia, 22 (1999): 9.

${ }^{29}$ González Muñoz, Una respuesta didáctica a la multiculturalidad, 7. 
Iberoamericanos en la década de los $90,{ }^{30}$ las investigaciones siguen evidenciado la necesidad de impulsar los elementos comunes y puntos de encuentro que expliquen los procesos históricos compartidos por los países de la región; ${ }^{31}$ aspecto éste ampliamente obviado en las normativas curriculares, provocando desajustes en el currículo español, tradicionalmente centrado en el período colonial, y en el latinoamericano, más vinculado a los procesos de independencia y conformación de los nuevos Estados. Asimismo, se concluye la necesidad de contribuir al desarrollo de una conciencia de pertenencia a un espacio compartido y diverso; insistir en la formulación de objetivos dirigidos al fomento de los valores éticos, afectivos y democráticos, y en la comprensión y respeto a otras culturas, mediante su completa visibilización; superar la perspectiva y periodización eurocéntrica hacia el equilibrio entre lo exterior e interior y, en éste, entre las culturas autóctonas y la europea; ampliar y profundizar en el tratamiento didáctico de las culturas prehispánicas, y revisar, hacia visiones más integradoras, el enfoque tradicional del proceso colonizador; definir e incorporar núcleos curriculares transversales, entre ellos, el fenómeno del mestizaje y los procesos de sincretismo cultural - ausentes en el currículo español-, apostando por los aspectos culturales, patrimoniales y sociales, explicativos, en buena medida, del medio social y cultural actual, en detrimento de adscripciones historiográficas positivistas de la historia de Iberoamérica.

Igualmente, sigue haciéndose necesaria la formulación de los objetivos específicos ya explicitada en el currículum-tipo de $1998 .{ }^{32}$ Por su relevancia en la consolidación del ECI, pueden destacarse los siguientes:

- Identificar las culturas que se han desarrollado en Iberoamérica a lo largo de la historia y conocer los rasgos básicos de cada una, así como las relaciones existentes entre ellas y la pervivencia de elementos de las mismas en la actualidad.

\footnotetext{
${ }^{30}$ Instituto de Estudios de Iberoamérica y Portugal. Universidad de Valladolid, «La enseñanza de la historia de Iberoamérica», 7-22.

${ }^{31}$ M. ${ }^{\text {a }}$ del Carmen González Muñoz, «La historia de Iberoamérica en la enseñanza secundaria: una propuesta didáctica», Íber: Didáctica de las Ciencias Sociales, Geografía e Historia, 54 (2007): 7-16.

${ }^{32}$ Instituto de Estudios de Iberoamérica y Portugal. Universidad de Valladolid, «La enseñanza de la historia de Iberoamérica».
} 
- Identificar y analizar las estructuras y los hechos políticos, económicos, sociales y culturales, así como las interrelaciones que se producen entre ellos, especialmente en los momentos de cambio.

- Vincular aquellas estructuras y hechos al contexto mundial en cada periodo histórico.

- Identificar y comprender las características, los valores y los problemas que son comunes a los países de Iberoamérica como consecuencia de un pasado común.

- Valorar la diversidad lingüística y cultural en Iberoamérica como derecho de los pueblos e individuos a su identidad, manifestando actitudes de tolerancia y respeto por otras culturas.

- Valorar y respetar el patrimonio cultural, lingüístico, artístico y social iberoamericano, asumiendo las responsabilidades que suponen su conservación y mejora, apreciándolo como fuente de disfrute y utilizándolo como recurso para el desarrollo individual y colectivo.

- Conocer las raíces históricas de la pluralidad étnica de la Iberoamérica actual y valorar el mestizaje como una de sus características fundamentales.

- Localizar informaciones referidas a la historia iberoamericana, verificarlas, clasificarlas y contrastar las procedentes de fuentes diversas para enjuiciar hechos históricos.

- Conocer y valorar diferentes perspectivas de análisis para un mismo hecho o proceso de la historia de Iberoamérica.

En relación con los contenidos, aún continúan vigentes las recomendaciones del currículum-tipo. Estas recomendaciones se basan en una selección de procesos y acontecimientos históricos, orientados al desarrollo de una cultura común, sin obviar las características propias que explican a cada comunidad y que la definen, en un equilibrio relevante entre lo particular y lo unitario. Entre las directrices metodológicas contempladas, especialmente ausentes en los currículos de Educación Primaria españoles, estos contenidos podrían conducirse hacia la aproximación del alumnado a la iconografía de las culturas precolombinas, al 
análisis textual y al patrimonio histórico-artístico para el tratamiento de la época colonial mediante las salidas escolares.

\section{LA CONSTRUCCIÓN DE LA IDENTIDAD CULTURAL IBEROAMERICANA EN LOS LIBROS DE TEXTO DE CONOCIMIENTO DEL MEDIO ESPAÑOLES}

\section{Interrogantes de investigación, objetivos y diseño metodológico}

A partir del estudio de uno de los materiales de concreción curricular de más incidencia en el ámbito educativo, seguimos los planteamientos de Ajagan Lester ${ }^{33}$ y los presupuestos de supervivencia del relato estereotipado y categorizado en narrativas y lenguajes visuales metonímicos. Desde estos presupuestos, la presente investigación plantea tres interrogantes de investigación, en torno a la articulación real de los principios y fines de la CCI y el Informe sobre la consolidación del Espacio Cultural Iberoamericano en su dimensión educativa: 1. ¿Qué tipo de "nosotros» y de «ellos» cultural proponen los libros de texto de Conocimiento del Medio españoles en el tratamiento didáctico de la Historia de Iberoamérica?, ¿quiénes se incluyen?, ¿quiénes son excluidos?; 2. ¿Qué imágenes identitarias propias y del "otro» son las que transmiten los temas dedicados a procesos históricos compartidos?; y 3. ¿En qué medida contribuyen a la consolidación del Espacio Cultural Iberoamericano?

El interés de estos interrogantes de investigación, bases para el análisis de la configuración de identidades culturales en el ámbito iberoamericano, radica en nuestras preocupaciones investigadoras acerca de las inherentes relaciones entre las políticas supranacionales, los currículos y los libros de texto de historia en Educación Primaria; la vinculación entre la enseñanza de la historia y la configuración de identidades culturales regionales; la construcción de una conciencia histórica alejada del estereotipo, delimitada en contenidos de naturaleza no enciclopédica y orientada hacia la profundización de los contenidos seleccionados; la integración y proximidad cultural entre los países que componen la comunidad iberoamericana, en orden a la consolidación de un Espacio

\footnotetext{
${ }^{33}$ Luis Ajagan Lester, «El texto escolar: apuntes para una didáctica crítica», en Primer Seminario Internacional de Textos Escolares. SITE 2006 (Santiago de Chile: Gobierno de Chile-UNESCO, 2007), 250-256.
} 
Cultural Iberoamericano diverso y plural; la función del libro de texto y de la enseñanza de la Historia en la construcción de la identidad cultural iberoamericana; y la determinación de los contenidos seleccionados, de los aspectos diferencialmente destacados, de la interpretación trascendente de las consecuencias del «encuentro», y de la omisión de otros contenidos de especial relevancia en la conformación de una verdadera conciencia identitaria iberoamericana.

La selección de contenidos escolares requiere interrogarse acerca de su pertinencia, su función social, su relevancia educativa y social, y sus fuentes informativas. Entre estas últimas, el libro de texto predomina como vehículo de la «cultura oficial» y garantía legitimadora de voces presentes y ausentes; ${ }^{34}$ paradójicamente, no son consultados como fuente por la ciudadanía, fuera de la institución escolar. Concretar las bases constituyentes de su prevalencia hegemónica exige del empleo de metodologías cualitativas. Desde este enfoque, adoptamos el análisis crítico del discurso con el propósito de revelar la intencionalidad didáctico-curricular $^{35}$ y la distorsión de realidades sociales y culturales — pasadas y presentes- en los procesos de selección de los contenidos escolares de Historia. ${ }^{36}$

A partir de su decodificación narrativa, normativo-curricular, iconográfica y procedimental, hemos abordado los contenidos escolares seleccionados, atendiendo a la construcción de las identidades de colectivos y culturas presentes y/o ausentes, sus interrelaciones y capacidad inclusiva en el ámbito cultural iberoamericano. Para ello, hemos considerado las potenciales distorsiones informativas en función de:

1. El silencio cultural.

2. La jerarquización de la realidad y de las culturas.

3. El énfasis en la diferencia cultural con voluntad separatista e individualizada —negación intercultural—.

\footnotetext{
${ }^{34}$ Michael W. Apple, «The text and cultural politics», Educational Researcher, 21 (7), (1992): 4-12.

${ }^{35}$ Jurjo Torres, El currículum oculto (Madrid: Morata, 1998).

${ }^{36}$ Jurjo Torres, «Diversidad cultural y contenidos escolares», Revista de Educación, 345 (2008): $83-110$.
} 
4. Atemporalidad descriptiva cultural, negando la dinámica evolutiva de las culturas y la génesis de nuevos paradigmas culturales (presentismo, culturas sin historia).

5. Desconexión con la realidad y con la problemática socio-cultural del entorno del alumnado español como ciudadano iberoamericano activo.

Para la constatación o refutación de estas distorsiones informativas, el análisis discursivo, de naturaleza descriptiva e interpretativa, permite conocer, mediante la observación sistemática y vaciado de datos, los conceptos, tratamiento didáctico y uso de los materiales curriculares de aula sin intervenir, de forma directa, en la realidad, bajo la visión del investigador.

Desde las teorías de la semiótica social y desde un modelo crítico-descriptivo, empleamos la técnica del análisis crítico del discurso, entendido éste como "el estudio del uso del lenguaje en las relaciones sociales», con el fin de investigar «los lazos entre los distintos rasgos lingüísticos de los textos [narrativos o visuales] y las estructuras culturales, sociales, junto a las relaciones y los procesos a los cuales pertenecen». ${ }^{37} \mathrm{El}$ análisis crítico del discurso se dedica a problemas sociales y permite, en consecuencia, "comprender, exponer y desenmascarar la desigualdad social», ${ }^{38}$ subyacente a contextos sociales y políticos específicos; las teorizaciones, descripciones y explicaciones derivadas del análisis se presentan, entonces, condicionadas socio-políticamente. ${ }^{39}$ A pesar de la diversidad teórica y analítica que comprende esta metodología, en función de la tipología textual, iconográfica u oral objeto de estudio, «los analistas críticos del discurso se harán preguntas sobre el modo en que las diversas estructuras de la dominación social se evidencian en el lenguaje», ${ }^{40}$ potenciando y/o justificando procesos, personas y acontecimientos, e invisibilizando/ ocultando otros.

\footnotetext{
${ }^{37}$ Mauricio Pilleux, «El análisis crítico del discurso», Documentos Lingüísticos y Literarios, 23 (2000): 37.

${ }^{38}$ Pilleux, «El análisis crítico del discurso», 37.

${ }^{39}$ Norman Fairclough y Ruth Wodak, «Critical discourse analysis», en Discourse as social interaction, ed. Teun A. Van Dijk (London: SAGE Publications, 1997), 259-284.

${ }^{40}$ Pilleux, «El análisis crítico del discurso», 39.
} 
De acuerdo con Fairclough-Wodak ${ }^{41}$ y Fairclough, ${ }^{42}$ en el agente productor o difusor del discurso textual reconocemos una acción mediadora entre el propio texto y la sociedad, determinando así tres planos o ámbitos de acción social: el texto, el nexo objeto de mediación y la sociedad, todos ellos situados en distintos niveles de elaboración y reelaboración discursiva, que en el contexto escolar se produciría en los mismas categorías.

El signo verbal e iconográfico, así como su articulación multimedia y/o digital, conforma la unidad de construcción discursiva, condicionada por un contexto físico, empírico — realidad de aula—, práctico, histórico y cultural específico - relación entre texto y contexto-, entre otras variables. Esta unidad se compone de una naturaleza ideológica, en tanto que en los agentes de su elaboración y utilización subyace una voluntad de influir y transformar el medio social y cultural del alumnado; posee una capacidad constructora de identidad, imaginario y percepción de la realidad, base para la configuración de representaciones sociales; ${ }^{43}$ dispone de un carácter histórico, heterogéneo y multimodal, en función de su sentido y, en menor medida, de su significado en el contexto discursivo.

Las narrativas históricas, los discursos iconográficos y el diseño de las actividades de aprendizaje, aislados en este estudio en unidades discursivas interdependientes, funcionan como soportes constitutivos del currículo - registros también de la memoria- y operan como modos de escritura de la cultura dominante; son responsables de la codificación e interpretación curricular, atribuyendo significaciones culturales y didácticas específicas y racionalizables, y núcleos expresivos de representaciones de las estructuras culturales que la escuela transmite.

En este sentido, el libro de texto aparece inherente a un discurso escolar que trasciende la transposición didáctica del discurso disciplinar, integrando, en su configuración, la adecuación de otros discursos como el institucional y el político. El contexto del discurso escolar, el aula, se

\footnotetext{
${ }^{41}$ Fairclough y Wodak, «Critical discourse analysis», 259-284.

${ }^{42}$ Norman Fairclough, «Propuestas para un nuevo programa de investigación del Análisis Crítico del Discurso", en Poder decir o el poder de los discursos, eds. Luisa Martín Rojo y Rachel Whittaker (Madrid: Arrecife, 1998), 35-54.

${ }^{43}$ Encarna Atienza y Teun A. Van Dijk, «Identidad social e ideología en libros de texto españoles de Ciencias Sociales», Revista de Educación, 353 (2010): 99-100.
} 
presenta así como espacio de construcción y negociación de saberes. ${ }^{44}$ De acuerdo a estos principios, abordamos nuestro análisis, a partir de dos planteamientos metodológicos: la problematización integrada del lenguaje verbal, iconográfico y procedimental del libro de texto, y la integración de las mediaciones institucionales y políticas. El estudio de la contribución del discurso del libro de texto de Ciencias Sociales a la mecanización de las prácticas sociales pasa por el análisis detallado del discurso, «una de las maneras más sofisticadas de estudiar las representaciones sociales que, de otra manera, serían invisibles, como el conocimiento, las ideologías y las identidades sociales». ${ }^{45}$

Partiendo de estos presupuestos, el análisis crítico de contenidos de los libros de texto se vincula al análisis crítico del discurso, concebido como producto, capaz de revelar ideologías subyacentes, y como instrumento, utilizado para la proyección, creación y retroalimentación de contenidos en las representaciones sociales e individuales. En este sentido, el análisis se dispondrá a interpretar la información contenida en los elementos semánticos y formales recogidos en los materiales curriculares seleccionados. Completamos el procedimiento de análisis con la incorporación de técnicas cualitativas para la recogida de datos cuantificables.

Bajo este enfoque cualitativo, la investigación se posiciona en un paradigma, básicamente, de carácter interpretativo. Igualmente, el estudio se considera próximo a la teoría fundamentada, pues, aunque no pretende la construcción de teorías para la explicación de una determinada realidad educativa a partir de sujetos concretos, busca la adopción de medidas para la implementación consciente y reflexionada de la dimensión del Espacio Cultural Iberoamericano en los materiales curriculares de mayor uso en las aulas iberoamericanas. El interés por el estudio de las identidades colectivas, como constructos sociales, históricos y culturales, parte de la consideración contextual de una de sus máximas concreciones: el libro de texto de Educación Primaria. La descripción y posterior

\footnotetext{
${ }^{44}$ Isabel Martins, «Analisando livros didáticos na perspectiva dos Estudos do Discurso: compartilhando reflexões e sugerindo uma agenda para a pesquisa», en O livro didático de Ciências: contextos de exi-gência, critérios de seleção, práticas de leitura e uso em sala de aula, eds. Isabel Martins, Guaracira Gouvêa y Rita Vilanova (Río de Janeiro: FAPERJ- Fundação Carlos Chagas Filho de Amparo à Pesquisa do Estado do Rio de Janeiro/UFRJ- Universidade Federal do Rio de Janeiro/NUTES- Núcleo de Tecnologia Educacional para a Saúde, 2012), 11-30.
}

${ }^{45}$ Atienza y Van Dijk, «Identidad social e ideología en libros de texto», 73. 
interpretación de los resultados obtenidos, como centros de análisis, responden, satisfactoriamente, a los principios de esta metodología.

Para el análisis de la información se propone un instrumento de investigación basado en un sistema de categorías que, a través de indicadores y descriptores, aborda, de forma integrada, la determinación de los núcleos conceptuales y el tratamiento didáctico que reciben los contenidos asociados a la conformación de la identidad cultural en la Educación Primaria española.

En la primera categoría de análisis se definen los materiales utilizados en la configuración de la imagen, abordando para ello su tipología patrimonial y género, mediante la determinación de las fuentes que la sustentan. En la realización de la primera variable de esta categoría se han considerado, en su mayor espectro, las expresiones y manifestaciones de la vida cotidiana de las comunidades objeto de análisis. Todas ellas han sido compendiadas en la tipología patrimonial, en orden a su capital importancia para la delimitación de identidades culturales, con base en las manifestaciones histórico-artísticas, la lengua, las creencias, las tradiciones, etc.

Con la segunda categoría se procede a la lectura visual del orden expositivo de los motivos iconográficos, definiendo la intensidad de impacto de la imagen en combinación con el texto que la secunda -impacto verbo-visual_- en atención a las relaciones proporcionales establecidas, su disposición y ubicación. Además, en esta categoría de análisis, se establece su grado y calidad de integración textual.

La tercera categoría aporta un marco organizativo para el análisis de las narrativas históricas textuales y de su contribución a la construcción de parámetros culturales, a través de procesos de superposición, negociación o síntesis.

De acuerdo con la revisión de la taxonomía de dominios del aprendizaje de Bloom por Anderson y Krathwohl, ${ }^{46}$ y con el objeto de comprobar el tratamiento metodológico de los contenidos que habrá de trabajar el alumnado, la adquisición de destrezas histórico-culturales y el desarrollo

\footnotetext{
${ }^{46}$ Lorin W. Anderson y David R. Krathwohl (eds.), A Taxonomy for Learning, Teaching, and Assessing: A Revision of Bloom's Taxonomy of Educational Objectives (Boston: Allyn \& Bacon-MA Pearson Education Group, 2001).
} 
de habilidades de pensamiento, la cuarta categoría de análisis atiende a los niveles de complejidad cognitiva y grado de problematización socio-cultural exigido en las actividades propuestas de las unidades didácticas seleccionadas. Según esto, se define la tipología de actividades en los cursos estudiados, considerando prioritarias las actividades referentes al trabajo de cualidades y expresiones culturales, manifestaciones artísticas y artes cultivadas. También se considera el tipo de recurso que utiliza y la ubicación de la actividad en el contexto de la unidad didáctica. En relación a los tipos de recursos empleados, el procedimiento de análisis de la actividad tendrá en cuenta las variables e indicadores de las Categorías I, II y III, contando con la posible incorporación de contenidos con un óptimo potencial interpretativo textual e iconográfico.

Finalmente, la quinta categoría valida la significación de los resultados anteriores en la dedicación temática del conjunto de los bloques de contenido incluidos, en su vinculación con el currículo oficial y en la propia programación didáctica editorial.

En tanto que los datos obtenidos son el resultado de filtros definidos por el investigador, el componente subjetivo en los resultados ha sido sometido a un proceso de triangulación. La triangulación de los datos textuales, iconográficos y procedimentales se inserta en el propio sistema de categorías propuesto, mediante el cotejo de la información obtenida en las prescripciones de las normativas curriculares y en las programaciones de aula de las editoriales objeto de estudio. Según este diseño metodológico, la imbricación del ámbito textual e iconográfico, junto al análisis-evaluación del diseño curricular y de los materiales curriculares propuestos, pretende, a partir de un único modelo de análisis, el establecimiento de relaciones discursivas completas.

La recogida de la información parte de la observación sistemática directa, a través del diseño de fichas codificadas de vaciado de datos ${ }^{47}$ generadas en el sistema de categorías descrito, previamente validado, tras su evaluación por especialistas en el área. Se han diseñado cuatro fichas de registro, a partir del sistema de categorías propuesto. Este sistema de categorías es, por tanto, el instrumento encargado de organizar

\footnotetext{
${ }^{47}$ Abelardo J. Soneira, «La «Teoría fundamentada en los datos» (Grounded Theory) de Glaser y Strauss», en Estrategias de investigación cualitativa, coord. Irene de Gialdino Vasilachis (Barcelona: Gedisa, 2006), 153-173.
} 
el contenido objeto de análisis y de estructurar las fichas para el vaciado de datos. Las técnicas adoptadas se concretan en el análisis documental de materiales curriculares y, de forma específica, del libro de texto, atendiendo, prioritariamente, a un tipo de contenido, el de carácter cultural, fundamental en la conformación de identidades culturales.

Mediante la utilización de estos instrumentos, hemos analizado los núcleos conceptuales y el tratamiento didáctico de la Historia de Iberoamérica, a partir de los materiales curriculares de mayor uso y difusión. El análisis de los textos escolares de Ciencias Sociales, verdaderas piezas discursivas, las imágenes didácticas que los completan, entendidas como documentos históricos, también de naturaleza discursiva, y de las actividades, necesariamente, se vincularán a su contribución en la formación de identidades culturales en el ámbito iberoamericano.

\section{Características de la muestra y criterios de selección}

Manejamos dos de las propuestas editoriales de mayor presencia en España: Santillana y Anaya. Los contenidos de las muestras editoriales pertenecen o aparecen vinculados al módulo temático del descubrimiento, conquista y colonización de América. La selección de las unidades didácticas, programaciones y guías didácticas, materiales complementarios para el alumno/a y para el profesor/a, y recursos impresos y digitales ha priorizado su dedicación a los procesos históricos y culturales producidos a partir de la llegada europea al continente americano, claves en la gestación del Espacio Cultural Iberoamericano.

Estos contenidos se encuentran específicamente contemplados en las propuestas editoriales de Anaya y Santillana para el cuarto y sexto cursos de Educación Primaria en España. ${ }^{48}$ Atenderemos, especialmente, al análisis textual, visual y procedimental de las consecuencias culturales de este proceso histórico, en orden a su capacidad explicativa de los fundamentos de imaginarios culturales.

\footnotetext{
${ }^{48}$ El período de realización de este proyecto de investigación se inició en el año 2012 y finalizó en los primeros meses de 2015. De acuerdo al calendario de implantación de la actual Ley Orgánica para la Mejora de la Calidad Educativa (LOMCE), los cursos de primero, tercero y quinto de Educación Primaria comenzaron su adaptación curricular en el curso escolar 2014-2015, razón por la que los materiales objeto de estudio -cuarto y sexo cursos- necesariamente concretan las líneas curriculares de la extinta Ley Orgánica de Educación (LOE).
} 
La muestra total considerada se compone de 16 conjuntos de materiales didácticos. ${ }^{49}$ La selección de los contenidos iconográficos, textuales y procedimentales se ha ajustado a tres criterios, reunidos en tres componentes/ámbitos:

Componente científico-técnico: los contenidos describen aspectos relevantes acerca de la expansión ultramarina europea, los descubrimientos geográficos, y los avances técnicos en navegación marítima y sus impulsores.

Componente social y cultural: los contenidos describen aspectos relevantes acerca de la sociedad y de la cultura europea y americana, priorizando el establecimiento de relaciones y repercusiones en su configuración.

Componente político: los contenidos describen aspectos sobre la administración de nuevos territorios.

En relación con los recursos iconográficos utilizados en el diseño y realización de las actividades, siempre que las imágenes seleccionadas presenten suficiente entidad, han sido analizadas siguiendo la metodología de análisis iconográfico sin que, por esta razón, se incluyan en los resultados generales iconográficos, pues forman parte, de forma autónoma, del análisis de las actividades.

\footnotetext{
${ }^{49}$ Propuesta editorial Anaya: Ricardo Gómez et al., Propuesta Didáctica. Conocimiento del Medio 6 (Madrid: Anaya, 2009); Recursos. Conocimiento del Medio 6 (Madrid: Anaya, 2009); Juan Ramón Brotons, Ricardo Gómez y Rafael Valbuena Conocimiento del Medio 6. Andalucía. Material para el profesorado. Recursos didácticos (Madrid: Anaya, 2009); CD-ROM para el profesorado. Conocimiento del Medio 4 (Madrid: Anaya, 2008); CD-ROM para el profesorado. Conocimiento del Medio 6 (Madrid: Anaya, 2009); Ricardo Gómez y Rafael Valbuena, Conocimiento del Medio 4. Castilla y León. Recursos didácticos y material para el profesorado (Madrid: Anaya, 2012); Ricardo Gómez Gil y Rafael Valbuena, Conocimiento del Medio 4. Castilla y León (Madrid: Anaya, 2008); Ricardo Gómez et al., Conocimiento del Medio 6. Andalucía (Madrid: Anaya, 2009).

Propuesta editorial Santillana: José Luis Alzu (ed.), 100 propuestas para mejorar la competencia en el conocimiento e interacción con el mundo físico (Madrid: Santillana, 2009); Lartaun de Egibar et al., Conocimiento del Medio 4. Aragón (Madrid: Santillana, 2008); Lartaun de Egibar et al., Conocimiento del Medio 4. Comunitat Valenciana (Madrid: Santillana, 2008); Lourdes Etxebarria y Ana Sánchez-Ramal (eds.), Conocimiento del Medio 6. Guí (Madrid: Santillana, 2009); Lourdes Etxebarria, et al., Conocimiento del Medio 6 (Madrid: Santillana, 2009); Mar García (ed.), Refuerzo y ampliación. Conocimiento del Medio 4 (Madrid: Santillana, 2008); Mar García (ed.), Refuerzo y ampliación. Conocimiento del Medio 6 (Madrid: Santillana, 2009); Ana Sánchez-Ramal (ed.), Más recursos. Conocimiento del Medio 6 (Madrid: Santillana, 2009).
} 
En cuanto a las vinculaciones entre las narrativas históricas y la iconografía seleccionada, cuando el texto de interés iberoamericano ha remitido a una imagen didáctica exenta de referentes en este sentido, ésta ha sido analizada y registrada en los resultados totales, igualmente; el texto - mediante la marcación de números—, en ocasiones, redirige a imágenes no ibero-americanistas, pero su discurso deriva en ellas. De forma inversa, este procedimiento también ha sido considerado, a partir de la imagen didáctica.

Por último, se ha procedido a la selección de contenidos, pertenecientes a los materiales multimedia e impresos complementarios, publicados por las editoriales seleccionadas. Aunque no constituyen unidades autónomas de análisis, sí se ha llevado a cabo un estudio descriptivo de los mismos.

Para alcanzar el nivel de contraste informativo deseado y una efectiva aproximación al caso español, han sido consultadas las normativas curriculares y libros de texto de dos países de la Comunidad Iberoamericana de Naciones: México y Chile. Los criterios de selección de estos dos países latinoamericanos han atendido al componente cultural y al grado de diversidad subyacente en sus sociedades. De un lado, la ausencia de unificación cultural en Latinoamérica es especialmente destacada, junto a otros países, en México. De otro, entre los países más homogéneos, se encuentra Chile. Ambos polos de análisis nos han permitido estudiar las estrategias educativas que, desde la Educación Básica, adoptan estos países para la consolidación del Espacio Cultural Iberoamericano, e integrar nuestras observaciones al análisis curricular y libros de texto de Educación Primaria en España.

Para las equivalencias de la Educación Primaria en Iberoamérica, manejamos las tablas elaboradas por los países firmantes del Convenio Andrés Bello, actualizada en julio de 2013.

\section{Análisis y discusión de resultados}

Puede afirmarse que el tratamiento didáctico del descubrimiento, conquista y colonización de América en los libros de texto de la Educación Primaria española, como fenómeno universal, propone un enfoque general europeísta, destacando la figura de Cristóbal Colón como perso- 
naje clave. En efecto, la propuesta editorial de Santillana para el cuarto curso de Primaria y, en relación a los aspectos culturales derivados de la expansión ultramarina, llega a obviar el continente americano, sus pueblos y sus aportaciones culturales, perdiendo, de este modo, una excelente oportunidad para trabajar la diversidad cultural e interculturalidad, definitorias de las sociedades actuales.

En la propuesta editorial de Anaya, para este mismo curso, el tratamiento didáctico de la Historia Moderna de América se reduce a la aproximación de los aspectos técnicos y científicos que posibilitaron los viajes de exploración: los progresos en los medios de transporte marítimo, y los avances en los instrumentos náuticos y cartográficos. Vagamente, aparecen contenidos sociales, económicos y culturales en este contexto.

Asimismo, a pesar de la insistencia curricular en el continente americano, no aparecen los grandes nombres de la expansión ultramarina; ni siquiera el de Cristóbal Colón o el de los Reyes Católicos, impulsores de la empresa. Únicamente, se nombra el continente americano, sin concretar detalles sobre los pueblos nativos o las grandes civilizaciones descubiertas por los europeos. Tampoco la administración de sus territorios tras los diversos procesos de conquista.

En su conjunto, puede afirmarse que la tendencia general se dirige, de forma igualitaria, hacia relaciones interculturales superpuestas y sin relación intercultural.

Tabla 1. Narrativa histórica e interculturalidad. Tipología. $4 .^{\circ}$ curso

\begin{tabular}{|c|l|c|c|}
\hline 4. $^{\mathbf{o}}$ curso & \multicolumn{1}{|c|}{ Tipología } & Frecuencia & Porcentaje válido \\
\hline \multirow{4}{*}{ Válido } & Superpuesta & 3 & 37,5 \\
\cline { 2 - 4 } & Negociada & 2 & 25,0 \\
\cline { 2 - 4 } & Sin relación intercultural & 3 & 37,5 \\
\cline { 2 - 4 } & Total & 8 & 100,0 \\
\hline
\end{tabular}

Aun asumiendo la ausencia predominante de relaciones culturales, destaca la narrativa de aspectos culturales que, intervinientes en un mismo proceso histórico protagonizado por más de una cultura, se realiza desde la descripción de elementos que obvia, niega u oculta otros, imprescindibles, sin embargo, para una comprensión completa del proceso. 
En relación a la propuesta editorial de Santillana para el sexto curso de Educación Primaria, el tratamiento de la Edad Moderna se concentra, precisamente, en el descubrimiento de América, en el imperio hispánico de Carlos v y Felipe ii, y en la dinastía borbónica. Los nombres de sus protagonistas, las fechas y hechos comienzan a adquirir mayor presencia y protagonismo. Sin embargo, el tratamiento didáctico de la repercusión social y cultural del descubrimiento de América es muy aproximado en el primer aspecto, y ausente en relación al segundo; sólo la última actividad analizada aborda elementos de naturaleza intercultural y espacial iberoamericana. Según esto, la descripción, interpretación y comparación de fuentes iconográficas o manifestaciones histórico-artísticas, la descripción y avances científicos y culturales, así como el conocimiento de la cultura y sociedad colonial y precolombina, se mantienen en un orden secundario y/o anecdótico.

Asimismo, de acuerdo con el registro de datos obtenidos, es sobresaliente la atemporalidad con la que se procede a la descripción de las culturas precolombinas, máxime cuando el currículo oficial atribuye, para este tercer Ciclo de Educación Primaria, las unidades de medida temporal a. C. / d. C. y de Edad.

La narración textual e iconográfica integral del descubrimiento de América sigue necesitando, en definitiva, una mayor aproximación a los actores sociales, a los rasgos culturales caracterizadores, a las aportaciones interculturales y a la germinación derivada de nuevos paradigmas culturales como el mestizaje, producto de las comunidades históricas que la generaron.

El manual de Anaya para este sexto curso asume una marcada perspectiva eurocéntrica, eludiendo, como ya se advierte en el análisis de la vinculación curricular de la propuesta:

- Los rasgos culturales de los pueblos precolombinos, inexistentes en la propuesta.

- Los imperios y culturas conquistados, así como sus protagonistas.

- Las características generales de la nueva sociedad colonial.

— La organización y administración de los territorios conquistados. 
- Contenidos patrimoniales de naturaleza iberoamericana y los procesos de evangelización, decisivos en la gestación de los nuevos paradigmas culturales.

Comprobamos que las acciones pedagógicas en Europa para la definición y tratamiento didáctico de lo que se ha venido en llamar dimensión europea, ha precedido, no muy coherentemente en relación a los países de la Península Ibérica, a una dimensión iberoamericana en la enseñanza de la historia de estos países, testigos, además, de importantes flujos migratorios en uno y otro lado del Atlántico. ${ }^{50}$ En efecto, los resultados obtenidos informan de la presencia de una importante tendencia - representada para el caso de los manuales de sexto curso en un $54.2 \%$ - hacia narrativas en las que la descripción de elementos culturales no eluden el encuentro con otros nuevos, determinando, sin precisión, su repercusión en las sociedades de origen y/o de destino. La deseable orientación hacia posiciones más sincréticas, representadas en un escaso $8.3 \%$ para este mismo curso de Educación Primaria, permitiría adoptar perspectivas en las que la descripción de elementos pudiera, desde la diversidad, trabajar nuevos paradigmas dimensionales culturales en las sociedades protagonistas.

Tabla 2. Narrativa histórica e interculturalidad. Tipología. 6. ${ }^{\circ}$ curso

\begin{tabular}{|c|l|c|c|}
\hline 6. $^{\mathbf{0}}$ curso & \multicolumn{1}{|c|}{ Tipología } & Frecuencia & Porcentaje válido \\
\hline \multirow{4}{*}{ Válido } & Superpuesta & 7 & 29,2 \\
\cline { 2 - 4 } & Negociada & 13 & 54,2 \\
\cline { 2 - 4 } & Sincrética/Sintética & 2 & 8,3 \\
\cline { 2 - 4 } & Sin relación intercultural & 2 & 8,3 \\
\cline { 2 - 4 } & Total & 24 & 100,0 \\
\hline
\end{tabular}

En función de los resultados de los análisis iconográficos, textuales, curriculares y de las actividades, detectamos la adopción general de perspectivas historiográficas políticas y, en menor medida, económicas, en detrimento de otras de índole social y cultural, determinantes en la consolidación del Espacio Cultural Iberoamericano. En este punto, se hacen evidentes las carencias descriptivas y didácticas en materia cultural, me-

\footnotetext{
${ }^{50}$ Rafael Valls, «La enseñanza española de la historia y su dimensión iberoamericana», Didáctica de las Ciencias Experimentales y Sociales, 26 (2012): 121-143.
} 
diante la invisibilidad de las culturas americanas; la ausencia de mapas toponímicos; la completa eliminación de los mecanismos de evangelización, fundamental en los procesos educativos coloniales, en la elaboración de las gramáticas de lenguas nativas, en la expansión lingüística y en el propio proceso colonizador; la ausencia de propuestas de análisis de obras histórico-artísticas y de manifestaciones patrimoniales (tangibles e intangibles) de factura iberoamericana, desplazadas por otras de origen europeo, entre otros núcleos temáticos presentes en la Educación Primaria de los países americanos de habla hispana.

Tabla 3. Iconografía patrimonial. Tipología. $4 .^{\circ}$ y 6 . $^{\circ}$ curso

\begin{tabular}{|c|c|c|c|}
\hline $4 .^{\circ}$ curso & $\begin{array}{c}\text { Iconografía patrimonial } \\
\text { europea }\end{array}$ & Frecuencia & Porcentaje válido \\
\hline \multirow{5}{*}{ Válido } & Pintura & 1 & 20,0 \\
\hline & Grabado y tejido & 1 & 20,0 \\
\hline & $\begin{array}{l}\text { Instrumentos, herramientas } \\
\text { y medios de transporte }\end{array}$ & 1 & 20,0 \\
\hline & $\begin{array}{l}\text { Fuentes documentales, } \\
\text { cartográficas y literarias }\end{array}$ & 2 & 40,0 \\
\hline & Total & 5 & 100,0 \\
\hline $6 .^{\circ}$ curso & $\begin{array}{c}\text { Iconografía patrimonial } \\
\text { europea }\end{array}$ & Frecuencia & Porcentaje válido \\
\hline \multirow{4}{*}{ Válido } & Arquitectura & 1 & 16,7 \\
\hline & Pintura & 3 & 50,0 \\
\hline & Grabado y tejido & 2 & 33,3 \\
\hline & Total & 6 & 100,0 \\
\hline
\end{tabular}

Además, la articulación de estas narrativas patrimoniales (también las de nuevo diseño) suele partir del carácter ventajoso-no ventajoso de los contenidos políticos que desarrollan $\left(25 \%\right.$ para $4 .^{\circ}$ curso y $30.76 \%$ para el $\left.6 .^{\circ}\right)$ y, de forma prioritaria, de su capacidad descriptiva $(62.5 \%$ para $4 .^{\circ}$ curso y $53.84 \%$ para el $6 .^{\circ}$ ). 
Tabla 4. Iconografía patrimonial y de nuevo diseño. Género. $4 .^{\circ}$ y $6 .^{\circ}$ curso

\begin{tabular}{|c|c|c|c|}
\hline 4. $^{\mathbf{o}}$ curso & Género & Frecuencia & Porcentaje válido \\
\hline \multirow{4}{*}{ Válido } & Político & 2 & 25,0 \\
\cline { 2 - 4 } & Judicial & 1 & 12,5 \\
\cline { 2 - 4 } & Demostrativo-descriptivo & 5 & 62,5 \\
\cline { 2 - 4 } & Total & 8 & 100,0 \\
\hline \multirow{2}{*}{$\mathbf{6 .}^{\mathbf{o}}$ curso } & Género & Frecuencia & Porcentaje válido \\
\hline \multirow{4}{*}{ Válido } & Político & 4 & 30,76 \\
\cline { 2 - 4 } & Judicial & 2 & 15,38 \\
\cline { 2 - 4 } & Demostrativo-descriptivo & 7 & 53,84 \\
\cline { 2 - 4 } & Total & 13 & 100,0 \\
\hline
\end{tabular}

Las frecuencias más bajas se registran en el género judicial, definido en la expresión narrativa de lo justo e injusto. Los materiales curriculares vinculados a este género constituirían un soporte especialmente útil para trabajar la evaluación de contenidos sociales con el alumnado, a partir de la emisión de juicios valorativos sobre el pasado y de sus consecuencias en el presente.

En relación con las actividades diseñadas para los materiales analizados, éstas no requieren, de forma general, altos niveles de complejidad cognitiva, ni fomentan, en consecuencia, habilidades de pensamiento de orden superior - un sorprendente $81.8 \%$ en los manuales de sexto curso, distribuido entre actividades de repetición y de compresión-.

Tabla 5. Actividades. Tipología. $4 .^{\circ}$ y $6 .^{\circ}$ curso

\begin{tabular}{|c|l|c|c|}
\hline 4. $^{\mathbf{0}}$ curso & \multicolumn{1}{|c|}{ Tipología } & Frecuencia & Porcentaje \\
\hline \multirow{4}{*}{ Válido } & Repetición & 6 & 35,3 \\
\cline { 2 - 4 } & Comprensión & 8 & 47,1 \\
\cline { 2 - 4 } & Aplicación, análisis y evaluación & 2 & 11,8 \\
\cline { 2 - 4 } & Creación & 1 & 5,9 \\
\cline { 2 - 4 } & \multicolumn{1}{|c|}{ Total } & 17 & 100,0 \\
\hline
\end{tabular}




\begin{tabular}{|c|l|c|c|}
\hline \multirow{2}{*}{ 6. $^{\mathbf{0}}$ curso } & \multicolumn{1}{|c|}{ Tipología } & Frecuencia & Porcentaje \\
\hline \multirow{4}{*}{ Válido } & Repetición & 17 & 51,5 \\
\cline { 2 - 4 } & Compresión & 10 & 30,3 \\
\cline { 2 - 4 } & Aplicación, análisis y evaluación & 6 & 18,2 \\
\cline { 2 - 4 } & Total & 33 & 100,0 \\
\hline
\end{tabular}

Tampoco emplean, por lo general, recursos textuales o iconográficos primarios, ni se incardinan, de forma progresiva y coherente, en el desarrollo de la unidad, abordando su tratamiento habitual en secciones finales.

Tabla 6. Actividades. Recurso. $4 .^{\circ}$ y $6 .^{\circ}$ curso

\begin{tabular}{|c|c|c|c|}
\hline $4 .^{\circ}$ curso & Recurso & Frecuencia & Porcentaje \\
\hline \multirow{7}{*}{ Válido } & Textual secundario & 7 & 41,2 \\
\hline & Icónico primario & 1 & 5,9 \\
\hline & Icónico secundario & 1 & 5,9 \\
\hline & Verbo-visual primario & 1 & 5,9 \\
\hline & Verbo-visual secundario & 5 & 29,4 \\
\hline & Externo & 2 & 11,8 \\
\hline & Total & 17 & 100,0 \\
\hline $6 .^{\circ}$ curso & Recurso & Frecuencia & Porcentaje válido \\
\hline \multirow{6}{*}{ Válido } & Textual primario & 1 & 3,0 \\
\hline & Textual secundario & 20 & 60,6 \\
\hline & Verbo-visual primario & 3 & 9,1 \\
\hline & Verbo-visual secundario & 8 & 24,2 \\
\hline & Externo & 1 & 3,0 \\
\hline & Total & 33 & 100,0 \\
\hline
\end{tabular}

La implementación de las propuestas curriculares habría de conducirse, en cambio, hacia la utilización de fuentes primarias documentales, uno de los soportes más importantes en la construcción del conocimiento histórico y social, y de fuentes primarias iconográficas, pues suponen uno de los instrumentos más interesantes para el fomento y desarrollo del pensamiento crítico e histórico, de las habilidades procedimentales y 
competencias básicas en potenciales unidades autónomas e interdependientes de investigación. ${ }^{51}$

La aplicación, análisis o evaluación de contenidos aparecen mayoritariamente sustituidos por procesos meramente reproductivos de la información, extremo que algunos manuales escolares de Conocimiento del Medio no han logrado solucionar con la sustitución del apartado final "actividades» por el de "practica tus competencias». En la línea de Sáiz, abordar, de forma eficaz, las competencias básicas en la enseñanza de la Historia «supondría una iniciación a tres capacidades cognitivas vinculadas al conocimiento histórico: la evaluación de evidencias o fuentes de información histórica, el razonamiento y la solución de problemas, y la creación de narrativas históricas». ${ }^{52}$ La formulación de preguntas-problema de aprendizaje sobre el pasado histórico en conexión con la configuración del presente, esto es, la propuesta de planteamientos de contenidos históricos de manera problematizada y vinculados a problemas relevantes de la actualidad, resultan de especial importancia. A partir de ellos, serían oportunos diseños de actividades en los que se demande al estudiante la creación de informes escritos y la comunicación de los resultados en un producto final, tras el manejo y contraste de fuentes primarias disponibles sobre un mismo núcleo temático.

A pesar de la insistencia curricular, y de las propias programaciones y guías didácticas de las editoriales objeto de estudio, son anecdóticas las actividades sobre el tratamiento de la información y competencia digital, pues su desarrollo en el aula deriva, unidireccionalmente, de la voluntad del docente y no del material didáctico disponible por el alumnado. Igualmente, la presencia de actividades de empatía histórica, de habitual desarrollo en el ámbito anglosajón, ${ }^{53}$ dirigidas a la adquisición de procedimientos y destrezas de la disciplina, y al desarrollo del pensamiento histórico, resulta especialmente particular.

\footnotetext{
${ }^{51}$ Delfín Ortega, «El tratamiento didáctico de la Historia e identidad cultural iberoamericanas en la Educación Secundaria Obligatoria española: modelo procedimental con fuentes iconográficas novohispanas», Clio. History and History teaching, 40 (2014): 1-23.

${ }^{52}$ Jorge Sáiz, «El tratamiento de las competencias básicas en los actuales libros de texto de historia en secundaria. Limitaciones y propuestas de mejora", Íber: Didáctica de las Ciencias Sociales. Geografía e Historia, 74 (2013): 59.

${ }^{53}$ Peter Lee y Rosalyn Ashby, «Empathy, perspective taking and rational understanding», en Historical empathy and perspective taking in the social studies, eds. Ozro L. Davis Jr., Elizabeth A. Yeager y Stuart J. Foster (Oxford: Rowman \& Little-field, 2001), 21-50.
} 
De acuerdo con las prescripciones de la CCI, consideramos fundamental, de un lado, la validación en el ámbito educativo del fenómeno del mestizaje como categoría histórico-cultural en la consolidación del Espacio Cultural Iberoamericano y, de otro, el análisis del grado de visibilización curricular de sus contribuciones en la Educación Primaria iberoamericana. ${ }^{54}$ Los resultados obtenidos de los análisis curriculares realizados informan del polarizado y también descoordinado tratamiento curricular de esta categoría, incluida y/o excluida, de forma desigual, de los núcleos temáticos y objetivos transversales, propios de las materias de Conocimiento del Medio e Historia en los países iberoamericanos contemplados -España, México y Chile-.

\section{CONCLUSIONES}

Equiparando el concepto de ciudadanía al de desarrollo humano en contextos multiculturales como el iberoamericano, ${ }^{55}$ y entendiendo la educación ciudadana como «el campo teórico y práctico donde se traducen, en acuerdos y desacuerdos, nuestras concepciones de la vida social y política», ${ }^{56}$ las relaciones inherentes a la enseñanza de la historia de Iberoamérica han sido conducidas, sin embargo, hacia la formación discursiva de límites territoriales y hacia la construcción de identidades nacionales. Aún hoy, la instrumentalización de la enseñanza de la historia, controladora de los tiempos sociales vinculados al destino de las naciones, sigue evidenciándose en la mayoría de los países miembros de la Comunidad Iberoamericana de Naciones y, especialmente, en los pertenecientes a la comunidad latinoamericana; un destino hegemónicamente político, racial, territorial y militar excluyente. ${ }^{57}$

Como hemos tenido ocasión de comprobar, el grado de integración curricular de contenidos sobre procesos históricos compartidos en el

\footnotetext{
${ }^{54}$ Delfín Ortega y Francisco Rodríguez Lestegás, «Iberoamérica en los currículos autonómicos de Ciencias Sociales de Educación Primaria: ¿realidad educativa o declaración de intenciones?» Didáctica de las Ciencias Experimentales y Sociales, 31 (2016): 39-60.

${ }^{55}$ M. ${ }^{a}$ de los Ángeles Sagastizabal (coord.), Aprender y enseñar en contextos complejos. Multiculturalidad, diversidad y fragmentación (Buenos Aires: Ediciones Novedades Educativas, 2006).

${ }^{56}$ François Audigier, L'éducation à la citoyenneté (Paris: INRP, 1999), 6. Citado en Joan Pagés, «Ciudadanía y enseñanza de la historia», Reseñas de enseñanza de la historia, 1 (2003): 11-42.

${ }^{57}$ Joyce Appleby, Lynn Hunt y Margaret Jacob, La verdad sobre la historia (Barcelona: Andrés Bello, 1994).
} 
ámbito iberoamericano, su tratamiento didáctico y su contribución a la conformación de identidades culturales en la Educación Primaria española resulta, aún hoy, insuficiente, no equitativa y descoordinada, con respecto a otros países miembros de la Comunidad Iberoamericana de Naciones; mientras las editoriales españolas dedican una escasa y poco consolidada actividad al tratamiento didáctico del legado cultural iberoamericano, los textos oficiales mexicanos y chilenos apuestan por su plena atención desde diversas dimensiones culturales y patrimoniales. ${ }^{58}$

De acuerdo con los resultados, insistimos en las propuestas de actuación prescritas en el Informe sobre la Consolidación del Espacio Cultural Iberoamericano de 2013, entre las que se hace necesaria la incorporación de contenidos de la cultura e historia iberoamericanas, con el objeto de reafirmar los componentes propios e identitarios en los currículos y de comprender las formas en las que las comunidades históricas se han relacionado con su entorno, construcciones colectivas transmitidas a las generaciones venideras y actualizadas en el presente. Y es que,

Si a lo largo de los contenidos de Ciencias Sociales no se potencia la visibilidad de continentes como América [...], más allá del conocimiento del mapa político [...] y accidentes geográficos, dejando totalmente al margen el conocimiento global de la pluralidad de culturas a nivel mundial, no se puede exigir al alumnado un conocimiento crítico de la población actual. ${ }^{59}$

Las aportaciones de la enseñanza de la historia a la educación de una ciudadanía iberoamericana han de contribuir a la capacitación y desarrollo del sentido crítico, del pensamiento social, la conciencia histórica y la historicidad de la realidad social iberoamericana, con el fin de participar en la misma, desde la intervención responsable, aspecto éste sorprendentemente ausente en el contexto curricular español. Desde la enseñanza de la historia de Iberoamérica, se hace preciso, entonces, el

\footnotetext{
${ }^{58}$ Delfín Ortega y Pilar Blanco, «Currículo e innovación en la enseñanza de la Historia. El tratamiento didáctico de la Historia de Iberoamérica y la construcción de identidades culturales en los currícula y libros de texto de Ciencias Sociales españoles, mexicanos y chilenos de Educación Primaria», en Una mirada al pasado y un proyecto de futuro: investigación e innovación en didáctica de las ciencias sociales, eds. Joan Pagès y Antoni Santisteban (Barcelona: Universitat Autònoma de Barcelona-Asociación Universitaria de Profesorado de Didáctica de las Ciencias Sociales, 2014), 279-288.

${ }^{59}$ Bellatti y Gámez, «La historia de Iberoamérica en los currículos escolares», 48.
} 
trabajo coordinado de las relaciones entre el pasado-presente-futuro, ${ }^{60}$ "pensarse en la historia» ${ }^{61}$ - piedra angular de la conciencia histórica- ${ }^{62}$ y la construcción reflexiva del sentido de temporalidad u orientación temporal y, en ella, la conformación de la cultura e identidad históricas $^{63}$ iberoamericanas. En este punto, el patrimonio histórico y sus relaciones con la ciudadanía se presentan como una óptima fórmula, siempre dirigido hacia un futuro inclusivo, mestizo y diverso, alejado de la exaltación de particularismos excluyentes. ${ }^{64}$ Bien es cierto, sin embargo, que en esta relación tridireccional cíclica de la conciencia histórica, la educación para una ciudadanía democrática de futuro, y la propia dimensión crítica en la que se inserta, ha tenido y tiene dificultades «para cohabitar con la dimensión identitaria», ${ }^{65}$ comprobable en los países que conforman hoy la Comunidad Iberoamericana de Naciones.

Sigue haciéndose necesaria la presencia de cuestiones sociales relevantes que contribuyan a la formación de la conciencia crítica del alumnado iberoamericano; a la relativización, análisis e interpretación de los hechos y procesos que formaron parte de la historia europea y americana; al desarrollo de su identidad personal y social, sobre el respeto, tolerancia y comprensión de otras identidades; y al rechazo frontal, sin ambages, de la exclusión y discriminación de cualquier naturaleza. ${ }^{66}$ Para ello, el conocimiento histórico escolar en los países de la comunidad iberoamericana habría de problematizar sus contenidos, fomentar los

${ }^{60}$ Bernard E. Jensen, «L'Histoire à l'école et dans la société en géneral: propos sur l'historicité de l'enseignement de cette discipline», en Détournements de l'histoire, ed. Conseil de l'Europe (Strasbourg: Conseil de l'Europe, 2000), 89-104.

${ }^{61}$ Nicole Tutiaux-Guillon y Marie J. Mousseau, Les jeunes et l'histoire. Identités, valeurs, conscience historique. Enquête européenne "Youth and History» (Paris: INRP, 1998).

${ }^{62}$ Carmen L. Cataño Balseiro, «Jorn Rüsen y la conciencia histórica», Historia y Sociedad, 21 (2011), 221-243.

${ }^{63}$ Christian Laville, «Pour une éducation historique critique, qu'attendre du courant de la conscience historique?», en Identités, mémoires, conscience historique, eds. Nicole Tutiaux-Guillon y Didier Nourrisson (Saint-Étienne: Université de Saint-Étienne, 2003), 13-25.

${ }^{64}$ Marie-Claude Muñoz, «Conclusions et Recommandations», en Le Patrimoine culturel et sa pédagogie: un facteur de tolérance, de civisme et d'intégration sociale, ed. Conseil de l'Europe (Bruxelles: Conseil de l'Europe, 1998), 119-124

${ }^{65}$ Audigier, L'éducation à la citoyenneté, 42. Citado en Pagés, "Ciudadanía y enseñanza de la historia», 11-42.

${ }^{66}$ Joan Pagès, «Educación cívica, formación política y enseñanza de las ciencias sociales, de la geografía y de la historia», Iber. Didáctica de las ciencias sociales, geografía e historia, 44 (2005): 45-55. 
estudios comparados y evitar los enfoques nacionales y/o territoriales, ${ }^{67}$ en aras del protagonismo de los hombres y mujeres, verdaderos artífices del devenir histórico. ${ }^{68}$

El desarrollo y adquisición de la perspectiva histórica en nuestros estudiantes implica, asimismo, la comprensión del impacto de las acciones humanas en la relación dialéctica que sostiene el concepto de conciencia histórica, y en el que la pluralidad de memorias e identidades han de permitir interrogar e interpretar el pasado, con el objeto de precipitar una verdadera conciencia ciudadana supranacional para la participación social y política y la proyección futura de la realidad iberoamericana.

\section{Nota sobre el autor:}

Delfín Ortega Sánchez es Profesor Contratado Doctor de Didáctica de las Ciencias Sociales en la Universidad de Burgos, Doctor en Didáctica de las Ciencias Sociales por dicha universidad y, además, Doctor en Historia de América por la Universidad de Extremadura. Su labor docente comenzó en las Universidades de Extremadura, Autónoma de Madrid y Granada, en las áreas de Historia de América y Didáctica de las Ciencias Sociales, respectivamente. Acreditado para la figura de Profesor Titular de Universidad, ha centrado sus intereses investigadores en la imagen didáctica como instrumento discursivo de índole política, social y religiosa en la América colonial, en los procesos de configuración de la identidad iberoamericana en la enseñanza de la Historia, en la Didáctica de la Geografía y las TIC en la formación del profesorado, y en los estudios de género en la Historia Moderna y en la formación inicial del profesorado. En torno a estos ámbitos de investigación, es autor de numerosas publicaciones, conferencias y ponencias invitadas en congresos y reuniones científicas de ámbito nacional e internacional.

Francisco Rodríguez Lestegás es Maestro de Primera Enseñanza (Lugo, 1969), Licenciado en Filosofía y Letras (Sección de Historia y Geografía,

\footnotetext{
${ }^{67}$ Joan Pagès, «Quelle est la place de l'identité national dans les apprentissages des élèves en histoire?», Le Cartable de Clio 11 (2011): 174-181.

${ }^{68}$ Delfín Ortega y Carlos Pérez, «Las mujeres en los libros de texto de Ciencias Sociales de $1^{\circ}$ de E. S. O.», en Una enseñanza de las ciencias sociales para el futuro: recursos para trabajar la invisibilidad de personas, lugares y temáticas, eds. Ana M. ${ }^{a}$ Hernández, Carmen R. García y Juan L. de la Montaña (Cáceres: Universidad de Extremadura-AUPDCS, 2015), 943-952.
} 
Santiago de Compostela, 1974), Doctor en Geografía e Historia (Sección de Geografía, Oviedo, 1984) y Licenciado en Filosofía y Ciencias de la Educación (Sección de Ciencias de la Educación, Santiago de Compostela, 1989). Catedrático de Universidad de Didáctica de las Ciencias Sociales en la Facultad de Formación del Profesorado de la Universidad de Santiago de Compostela (Campus de Lugo), en la que desempeña el cargo de Decano desde 2011. Con anterioridad, ha sido Director de Departamento durante más de veinte años. Como resultado da su actividad investigadora, tiene publicados siete libros: Valor y usos del suelo urbano en Lugo, Os ríos galegos. Morfoloxía e réxime (en coautoría con F. J. Río Barja), Didáctica das Ciencias Sociais na Educación Infantil, La actividad humana y el espacio geográfico, Manual de aprendizaxe e ensinanza de Xeografía e Ciencias Sociais para educación secundaria (en coautoría con X. C. Macía Arce y F. X. Armas Quintá), así como las obras colectivas Identidad y ciudadaní. Reflexiones sobre la construcción de identidades (coordinador) y Ensinar Geografia. Realidades e propostas no Brasil e Galiza (coordinador con X. C. Macía Arce y F. X. Armas Quintá). También es autor de numerosos capítulos incluidos en obras de autoría colectiva y artículos publicados en revistas especializadas en temas de geografía, didáctica de las ciencias sociales, formación del profesorado y educación en general.

\section{Referencias:}

AJAGAN LESTER, Luis. «El texto escolar: apuntes para una didáctica crítica». In Primer Seminario Internacional de Textos Escolares. SITE 2006. Santiago de Chile: Gobierno de Chile-UNESCO, 2007.

AlBert, Joan Miquel, y Concha FuENTES. «Enseñanza de la historia y construcción de identidades culturales en centros escolares iberoamericanos y españoles». Íber: Didáctica de las Ciencias Sociales, Geografía e Historia 75 (2013). ALzU, José Luis, ed. 100 propuestas para mejorar la competencia en el conocimiento e interacción con el mundo físico. Madrid: Santillana, 2009.

Anderson, Lorin W. y David R. Krathwohl, eds. A Taxonomy for Learning, Teaching, and Assessing: A Revision of Bloom's Taxonomy of Educational Objectives. Boston: Allyn \& Bacon-MA Pearson Education Group, 2001.

APPLE, Michael W. «The text and cultural politics.»Educational Researcher 21 (7) (1992).

ApplebY, Joyce, Lynn Hunt y Margaret JACOB. La verdad sobre la historia. Barcelona: Andrés Bello, 1994. 
ARISTA, Verónica, Felipe BonILla and Laura H. Lima. "Los manuales escolares y su uso en el aula». Íber: Didáctica de las Ciencias Sociales, Geografía e Historia 70 (2012).

Atienza, Encarna, y Teun A. VAN DiJK. «Identidad social e ideología en libros de texto españoles de Ciencias Sociales». Revista de Educación 353 (2010).

AudigIER, François. L'éducation à la citoyenneté. Paris: INRP, 1999.

Bellatti, Ilaria, y Virginia GÁmEz. «La historia de Iberoamérica en los currículos escolares: Un enfoque intercultural». Íber: Didáctica de las Ciencias Sociales, Geografía e Historia 75 (2013).

Brotons, Juan Ramón, Ricardo Gómez y Rafael Valbuena. Conocimiento del Medio 6. Andalucía. Material para el profesorado. Recursos didácticos. Madrid: Anaya, 2009.

CAmpos CHÁvez, Carolina. "Identidad nacional y enseñanza de la historia en la escuela. Una aproximación al caso mexicano y chileno». PhD diss., Universidad Michoacana de San Nicolás de Hidalgo, 2012.

CARretero, Mario. Documentos de identidad. La construcción de la memoria histórica en un mundo global. Buenos Aires: Paidós, 2007.

CARretero, Mario, y María SARTI. «Notas sobre la enseñanza de la historia en Iberoamérica. La centralidad de las narrativas nacionales». Íber: Didáctica de las Ciencias Sociales, Geografía e Historia 75 (2013).

Carta Cultural Iberoamericana, 2006. Accessed March 13, 2012. http://www.culturasiberoamericanas.org/carta_cultural.php

CATAÑo BAlseiro, Carmen L. "Jorn Rüsen y la conciencia histórica». Historia y Sociedad 21 (2011): 221-243.

DíAz BARRADo, Cástor. "Algunas reflexiones sobre la identidad en el seno de la Comunidad Iberoamericana de Naciones». Investigación \& Desarrollo 21 (2) (2013).

FAIRCLOUGH, Norman. «Propuestas para un nuevo programa de investigación del Análisis Crítico del Discurso». In Poder decir o el poder de los discursos, edited by Luisa Martín Rojo and Rachel Whittaker. Madrid: Arrecife, 1998.

FAIRCLOUgh, Norman, y Ruth WodAK. «Critical discourse analysis». In Discourse as social interaction, edited by Teun A. Van Dijk. London: SAGE Publications, 1997.

Fuentes, Concha, y Virginia GÁMEz. «¿Qué saben los alumnos de secundaria de la geografía iberoamericana?». In Innovación en la enseñanza de la geografía ante los desafíos sociales y territoriales, edited by Rafael de Miguel, M. ${ }^{a}$ Luisa de Lázaro y Torres and M. ${ }^{a}$ Jesús Marrón. Zaragoza: Institución Fernando el Católico, 2013.

GARcía CASAS, Fernando. «Un lugar para la Comunidad Iberoamericana». Política exterior 27 (151) (2013). 
GonzÁlez MuÑoz, M. ${ }^{a}$ del Carmen. Una respuesta didáctica a la multiculturalidad: el tratamiento en las aulas de Educación Secundaria de la historia común de Iberoamérica. Madrid: Viceconsejería de Educación de la Comunidad de Madrid / Subdirección General de Inspección Educativa, 2005.

- «La historia de Iberoamérica en la enseñanza secundaria: una propuesta didáctica». Íber: Didáctica de las Ciencias Sociales, Geografía e Historia 54 (2007).

Informe sobre la consolidación del Espacio Cultural Iberoamericano 2013. Accessed February 7, 2014. http://segib.org/es/node/9150

Instituto de Estudios de Iberoamérica y Portugal. Universidad de Valladolid, «La enseñanza de la historia de Iberoamérica», Íber: Didáctica de las Ciencias Sociales, Geografía e Historia, 22 (1999): 7-22.

JENSEN, Bernard E. «L'Histoire à l'école et dans la société en géneral: propos sur l'historicité de l'enseignement de cette discipline». In Détournements de l'histoire, edited by Conseil de l'Europe, 89-104. Strasbourg: Conseil de l'Europe, 2000.

LAVILlE, Christian. "Pour une éducation historique critique, quattendre du courant de la conscience historique?». In Identités, mémoires, conscience historique, edited by Nicole Tutiaux-Guillon and Didier Nourrisson, 13-25. Saint-Étienne: Université de Saint-Étienne, 2003.

LEE, Peter, y Rosalyn AsHBY. "Empathy, perspective taking and rational understanding». In Historical empathy and perspective taking in the social studies, edited by Ozro L. Davis Jr., Elizabeth A. Yeager and Stuart J. Foster, 21-50. Oxford: Rowman \& Little-field, 2001.

MARCHESI, Álvaro, coord. Avanzar en la construcción de un espacio cultural compartido. Desarrollo de la Carta Cultural Iberoamericana. Madrid: Organización de Estados Iberoamericanos para la Educación, la Ciencia y la Cultura, 2012.

MARTINS, Isabel. «Analisando livros didáticos na perspectiva dos Estudos do Discurso: compartilhando reflexões e sugerindo uma agenda para a pesquisa». In O livro didático de Ciências: contextos de exi-gência, critérios de seleção, práticas de leitura e uso em sala de aula, edited by Isabel Martins, Guaracira Gouvêa and Rita Vilanova, 11-30. Río de Janeiro: FAPERJ- Fundação Carlos Chagas Filho de Amparo à Pesquisa do Estado do Rio de Janeiro/UFRJ- Universidade Federal do Rio de Janeiro/NUTES- Núcleo de Tecnologia Educacional para a Saúde, 2012.

Miralles, Pedro, y Sebastián Molina. «La importancia de los referentes nacionales en el aprendizaje de las Ciencias Sociales: una investigación con alumnado iberoamericano». Íber: Didáctica de las Ciencias Sociales, Geografía e Historia 75 (2013). 
MuÑoz, Marie-Claude. "Conclusions et Recommandations». In Le Patrimoine culturel et sa pédagogie: un facteur de tolérance, de civisme et d'intégration sociale, edited by Conseil de l'Europe. Bruxelles: Conseil de l'Europe, 1998.

Organización de Estados Iberoamericanos. «Cátedra de Historia de Iberoamérica. Documento programático 2001». Accessed March 3, 2012. http://www.campus-oei.org/cathistoria/.

- «Iberoamérica: unidad cultural en la diversidad». Accessed March 3, 2014. http://www.dgri.sep.gob.mx/formatos/4_oei_13.pdf.

ORTEGA, Delfín. «El tratamiento didáctico de la Historia e identidad cultural iberoamericanas en la Educación Secundaria Obligatoria española: modelo procedimental con fuentes iconográficas novohispanas». Clio. History and History teaching 40 (2014): 1-23.

OrTega, Delfín, y Carlos PÉrez. "Las mujeres en los libros de texto de Ciencias Sociales de $1 .^{\circ}$ de E. S. O.». In Una enseñanza de las ciencias sociales para el futuro: recursos para trabajar la invisibilidad de personas, lugares y temáticas, edited by Ana M. ${ }^{a}$ Hernández, Carmen R. García y Juan L. de la Montaña, 943-952. Cáceres: Universidad de Extremadura-AUPDCS, 2015.

Ortega, Delfín, y Francisco Rodríguez Lestegás. «Iberoamérica en los currículos autonómicos de Ciencias Sociales de Educación Primaria: ¿realidad educativa o declaración de intenciones?». Didáctica de las Ciencias Experimentales y Sociales 31 (2016): 39-60.

Ortega, Delfín, y Pilar Blanco. «Currículo e innovación en la enseñanza de la Historia. El tratamiento didáctico de la Historia de Iberoamérica y la construcción de identidades culturales en los currícula y libros de texto de Ciencias Sociales españoles, mexicanos y chilenos de Educación Primaria». In Una mirada al pasado y un proyecto de futuro: investigación e innovación en didáctica de las ciencias sociales, edited by Joan Pagès and Antoni Santisteban, 279-288. Barcelona: Universitat Autònoma de Barcelona-Asociación Universitaria de Profesorado de Didáctica de las Ciencias Sociales, 2014.

PAGÈs, Joan. "Educación cívica, formación política y enseñanza de las ciencias sociales, de la geografía y de la historia». Iber. Didáctica de las ciencias sociales, geografía e historia 44 (2005): 45-55.

- «Quelle est la place de l'identité national dans les apprentissages des élèves en histoire?». Le Cartable de Clio 11 (2011).

- "Ciudadanía y enseñanza de la historia». Reseñas de enseñanza de la historia 1 (2003): 11-42.

PilleuX, Mauricio. «El análisis crítico del discurso». Documentos Lingüísticos y Literarios 23 (2000). 
Sagastizabal, M. ${ }^{a}$ de los Ángeles, coord. Aprender y enseñar en contextos complejos. Multiculturalidad, diversidad y fragmentación. Buenos Aires: Ediciones Novedades Educativas, 2006.

SÁIz, Jorge. «El tratamiento de las competencias básicas en los actuales libros de texto de historia en secundaria. Limitaciones y propuestas de mejora». Íber: Didáctica de las Ciencias Sociales. Geografía e Historia 74 (2013).

Sánchez-Ramal, Ana, ed. Más recursos. Conocimiento del Medio 6. Madrid: Santillana, 2009.

SONEIRA, Abelardo J. «La «Teoría fundamentada en los datos» (Grounded Theory) de Glaser y Strauss». In Estrategias de investigación cualitativa, edited by Irene de Gialdino Vasilachis, 153-173. Barcelona: Gedisa, 2006.

ToRRES, Jurjo. «Diversidad cultural y contenidos escolares». Revista de Educación 345 (2008): 83-110.

- El currículum oculto. Madrid: Morata, 1998.

Tutiaux-Guillon, Nicole, y Marie J. Mousseau. Les jeunes et l'histoire. Identités, valeurs, conscience historique. Enquête européenne "Youth and History». Paris: INRP, 1998.

VALLS, Rafael. «La enseñanza española de la historia y su dimensión iberoamericana». Didáctica de las Ciencias Experimentales y Sociales 26 (2012): 121-143.

XXIII Cumbre Iberoamericana de Jefes de Estado y de Gobierno 2013. Accessed February 11, 2014. http://segib.org/es/node/8417. 